\section{Independence, but no Nobel winners for India since then}

[NEW DELHI] As India celebrates the fiftieth anniversary of its independence today (14 August), many are asking why no Indian scientist has been awarded a Nobel prize in the post-independence era. India's only Nobel winner in science, Chandrasekhara Venkata Raman, was a product of British times; so were Srinivasa Ramanujan, the eminent mathematician, the astrophysicist Meghnad Saha, and Satyendra Bose, of boson fame.

Independent India invested $\$ 50$ billion in setting up a huge infrastructure which included about 120 university institutes of technology, and 100 national laboratories, which the country's first prime minister, Jawaharlal Nehru, called "temples of science". But these temples failed to produce gods of the stature of Raman or Bose.

According to leading contemporary Indian scientists, the reason is not difficult to find. "Our system in national labs or universities discourages initiative, innovation or inspiration," says Jayant Narlikar, a prominent astronomer. "It is geared to the progress of the average scientist... as a society, we are uncomfortable with excellence."

Many feel that one mistake India made was to let an excellent university system steadily decay. "Massive reforms are now needed to save these sinking institutions," says Chintamani Nageswara Rao, chairman of the cabinet committee on science and technology. The future of science in India, says Rao, depends on a small percentage of the best young talent who remain working in the few institutions still able to offer good research facilities.

This does not mean that Indian scientists have no reason to rejoice over the golden jubilee of independence. Over the past 50 years, Indian science has eliminated famines, improved life expectancy and brought satellites, supercomputers and atomic power. Food production has increased fourfold, and India is now the world's second-largest milk producer, after the United States.

"But research failed to eradicate poverty or control population growth," says Govindarajan Padmanabhan, director of the Indian Institute of Science in Bangalore.

Rajesh Kochhar, a historian of science, argues that science has failed to make a greater impact because most research in independent India has been carried out with a greater emphasis on achieving personal recognition abroad - a passport to promotion at home - than on its importance in an Indian context. "The Indian nuclear, space and missile programmes constitute science in an extended sense of the term, but are no more than successful applications of known technologies," he says.

K.S.Jayaraman

\title{
Make marijuana research easier, panel urges NIH
}

[SAN FRANCISCO] The US National Institutes of Health (NIH) has been urged by a panel of scientific advisers to set up a centralized mechanism to facilitate the design and conduct of studies of the potential therapeutic effects of marijuana.

In giving its support to such studies, the report, based on a meeting held in Bethesda, Maryland, earlier this year (see Nature 385, 756; 1997), argues that science should be separated from the public debate about the potential harm of non-medical marijuana use.

There is no indication yet as to whether the NIH will take up these recommendations. In a statement, Harold Varmus, the director of $\mathrm{NIH}$, said merely that marijuana studies would go through the normal competitive peer review process for funding. "We want to make clear what has always been the case $\mathrm{NIH}$ is open to receiving research grant applications for studies of the medical efficacy of marijuana," said Varmus.

But in principle, the report, released in Washington DClast Friday, could both stimulate further research on marijuana's medical effects and ease the implementation of controversial laws passed last year in California and Arizona that allow doctors to recommend it (see Nature 384,$95 ; 1996)$.

The California Assembly appropriations committee is currently considering legislation that would create a medical marijuana research programme within the University of California, and allocate $\$ 1$ million to its first year of operation.

"This beginning of a thaw on the federal level is a good sign that by the time we're ready to do research, we'll have a partner in NIH, not an enemy," says a senior staffer for California Senator John Vasconcellos (Democrat, San Jose), who introduced the bill.

In its executive summary, the advisory panel asks the NIH to consider administrative mechanisms to encourage grant applications for research into the use of marijuana for appetite stimulation, nausea following anticancer therapy, neurological and movement disorders, analgesia and glaucoma.

"For at least some potential indications, marijuana looks promising enough to recommend that there be new controlled studies done," the committee chair, William Beaver, professor of pharmacology and anaesthesia at Georgetown University School of Medicine, says in the report.

The panel was made up of eight experts with backgrounds in clinical studies and therapeutics. According to panel member Reese Jones, professor of psychiatry at the University of California in San Francisco, one reason for the decline in interest in marijuana research is that the easiest work has already been done, while the more problematic studies have faced a number of hurdles that have made it difficult to pass peer review.

Some of these problem areas include the side-effects of the drug, placebo controls, dose titration, blinding and selection of clinical endpoints. The panel recommends various solutions, for example that the NIH prioritizes the development of a smoke-free inhaled delivery system designed to remove the significant hazards of marijuana's combustion by-products.

Despite these hurdles, marijuana research should not be ignored, says the panel, adding that there may be compounds in the leaf that are not present in capsule delta-9tetrahydrocannabinol (THC), the major active ingredient in marijuana smoke, and that the pharmacokinetics and bioavailability of the two are quite different. Some physicians argue that smoking marijuana is more effective than the THC pills in suppressing nausea in cancer patients and stimulating appetite in AIDS patients.

It also pointed out that the difficulties of gaining access to study material have often discouraged researchers. For example, the National Institute on Drug Abuse (NIDA), which grows marijuana for research, has resisted supplying marijuana for therapeutic studies out of fear that it would send the wrong message to the public. The panel recommends that NIH ensures that adequate supplies are available to investigators.

A spokesman for Barry McCaffrey, director of the White House Drug Policy Office, has welcomed the report. "We have said from the start that this is an issue for the medical and scientific community, and not for politics," he told the Washington Post.

The full text of the report is available on http://www.nih.gov/news/medmarijuana/ MedicalMarijuana.htm. SallyLehrman

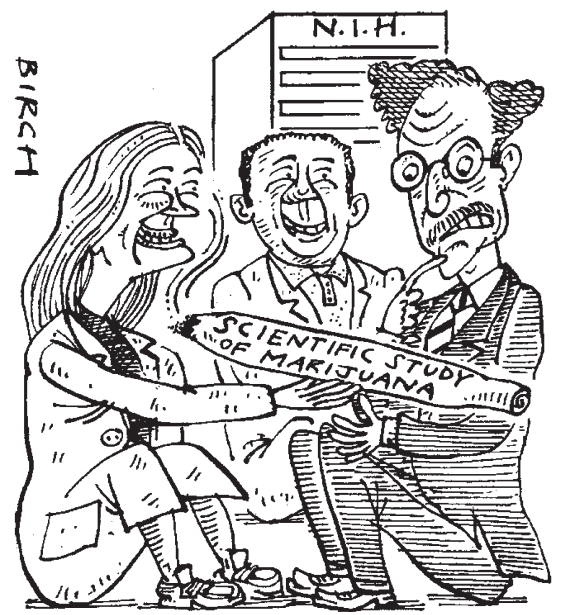

